\title{
A Corpus-Based Investigation Into \\ “Conversationalization” in the Discourse of Magazine*
}

\author{
ZHU Hong-qiang \\ Jinan University, Guangzhou, China
}

\begin{abstract}
Media discourse is featured as "conversationalization" and many other discourse analysts suggest that the text type in some other discourses shifts from the generic feature of "writing” to the genre of "speech", which indicates that this change is manifest in its style moving from "being informal" towards "being formal". Drawing on the methodological insights from corpus linguistics, the paper investigates the use of discourse markers, an indicator of “conversational” style, in English magazines (e.g., TIME) via the corpora such as British National Corpus (BNC), TIME, and Corpus of Contemporary American English (COCA). The results show that there is an increasing tendency in the use of discourse markers within 30 years spanning from the 1980s to 2000s and the different interpersonal meanings of discourse markers are relevant to the different generic sections of its coverage in the magazine. In addition, one of the discourse markers- "you know" taken as an instance is under survey. The analysis suggests that the discourse function of "you know" changes from being "evidential” towards being “evaluative”.
\end{abstract}

Keywords: media discourse analysis, conversationalization discourse markers, corpus linguistics

\section{Introduction}

Conversationalization (Fowler, 1988; Fairclough, 1992) is one of the key concepts in the studies of contemporary media discourse and thus draws interests of many critical linguists. For instance, Fairclough (1992) examines the television discourse and asserts that media discourse as one of the social public discourses has shifted to "conversationalization". The critical linguists (Fowler, 1988, 1991; Hundt \& Mair, 1999; Biber, 2003) observe that the language of newspaper is featured with the conversational style. Seen from the perspective of diachronic change of text type, there may emerge a shift from being spoken to written or vice versa in some of the other public discourses. For instance, drawing upon a comparative method, Atkinson (1992) suggests that text type in the medical discourse within 1735-1985 appears to be changing from being "narrative” to "overt expression of persuasion”. By contrast, Biber and Finegan $(1989,1992)$ explore the usage of "drift" among piles of written and spoken texts and suggest that the semantic grammar of "drift" seems to moving toward being more "written” than being "spoken”. Moreover, Baron (2003) analyzes the stylistic features of English email text and proposes that colloquial style as featured in the discourse of digital discourse corresponds with the social attitude due to the social change.

\footnotetext{
* This paper is supported by the Humanities and Social Sciences Project granted by the Ministry of Education, P.R.C., "Institutional Discourse Studies in the Chinese Context: A Perspective of Appraisal Theory”, Grant Number: 13 YJC740028. ZHU Hong-qiang, lecturer, Ph.D. candidate, College of Foreign Studies, Jinan University.
} 
The previous studies in the above review share the following characteristics: Firstly, the studies approach the feature of "conversationalization" manifested in the public discourse-with the particular reference to the various mediated discourses such as newspaper discourse, email texts, television discourse, and medical discourse. Secondly, although these approaches to the discourses analysis are various but they tend to be more concerned with the analysis of linguistic structures represented. For example, Fairclough's assertion is grounded on the analysis of television interview and believes that television interview is based on the simulated "mundane" conversation, which draws on the use of direct reported speech, colloquialized lexis and idioms, and use of various pronouns. Fowler $(1988,1991)$ attempts to explore conversational styles in the print news media in terms of the following linguistic categories: the format of layout, register, syntax and morphology, deixis and the system of modality, etc.. Biber (2003) suggests that the news articles appear to be more informative than academic papers. Hundt and Mair (1999) summarize several stylistic properties owned by the language of newspaper, i.e., the use of the second personal pronouns, the use of contractions, the initialization of connectives, verbal phrases and the use of progressives and suggest these properties are challenging the "standard norms" of written English.

Based on the above considerations, the present study draws upon the insight of corpus linguistics and aims to investigate the change of text type with the special focus on "conversationalization" represented in the English magazine discourse. The starting hypothesis holds that apart from those stylistic features observed by the previous studies to distinguish the spoken from the written style, one of the other features might be the use of discourse markers in the communication. In other words, the discourse markers tend to be more frequently used in spoken discourse than written discourse. The functions of discourse markers in English are hugely various from one variety to another and it appears to be unlikely to exhaust all the uses of discourse markers in one study. Therefore, the present study is based on a selection of the discourse markers in English to explore the uses of them in the English magazine discourse via several corpora. The selection of discourse markers includes “you know”, “I mean”, “oh yeah”, “anyway”, “actually”.

\section{Research Questions and Methodology}

The present study aims to respond to the following questions:

(1) Does "conversationalization” appear in the discourse of magazine?

(2) What are the uses of discourse markers across the different generic sections in magazine coverage?

(3) What are the collocations of discourse markers across the different generic texts in magazine discourse?

By combining data-driven and hypothesis-driven approaches, the research questions are posed to explore via the sub-corpora of British National Corpus (BNC), i.e., BNC, Corpus of Contemporary American English (COCA), and TIME in terms of the attributes of each corpus. The analytic tools include "Frequency" and "Concordance" and the results of search will be reported in "Chart".

\section{Results and Analysis}

A selection of discourse markers is investigated with the following steps in order to respond to the research questions:

(1) A synchronic investigation is made into the uses of discourse markers in the corpus of BNC and then this will produce the proportional distribution of the discourse markers among the different sub-sections such as 
spoken, fiction, magazine, newspaper, etc..

(2) A diachronic survey is conducted within the corpus of TIME within 90 years with the aim to look into how the uses of discourse markers undergo a historical change in the defined media discourse-magazine discourse.

(3) The uses of discourse markers will be examined in the both COCA and TIME in order to identify the preferences of them within the different sections of magazine discourse.

Following the above steps, the selected five discourse markers, i.e., "you know”, “I mean”, "oh, yeah”, "anyway", "actually", are searched on the BNC platform. Formally, the five searchable linguistic items are added with the "comma” before and after (i.e., “, you know,”, “, I mean,”, “, oh, yeah,”, “, anyway,”, “, actually,") and this will ensure that the results of the research appear as discourse markers.

For instance, the search result of "you know" is shown in the following chart.

\begin{tabular}{|c|c|c|c|c|c|c|c|c|}
\hline \multicolumn{3}{|c|}{$\begin{array}{l}\text { CLICK ON BARS FOR } \\
\text { CONTEXT }\end{array}$} & \multicolumn{6}{|c|}{$\begin{array}{l}\text { CLICK ON COLUMN HEADINGS FOR FREQUENCY IN SUB- } \\
\text { SECTION }\end{array}$} \\
\hline SECTION & SPOKEN & FICTION & MAGAZINE & NEWSPAPER & NON-ACAD & ACADEMIC & MISC & \\
\hline FREQ & 5003 & 547 & 37 & 16 & 49 & 50 & 45 & \\
\hline PER MIL & 502.12 & 34.38 & 5.10 & 1.53 & 2.97 & 3.26 & 2.16 & SECTION \\
\hline $\begin{array}{c}\text { SEE ALL } \\
\text { SUB-SECTIONS } \\
\text { AT ONCE }\end{array}$ & & & & & & & & $\begin{array}{l}\text { \# TOKENS } \\
\mathbf{5 0 0 3} \\
\text { SIZE } \\
\mathbf{9 , 9 6 3 , 6 6 3}\end{array}$ \\
\hline & & 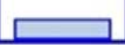 & & & & & & PER \\
\hline
\end{tabular}

Chart 1. Occurrence of "you know” in BNC.

In Chart 1, "you know" is identified within the spoken section with a markedly frequency of 502.12 token/million, the highest among all the sections such as "fiction”, "magazine”, "newspaper", and so on. Likewise, the other four discourse markers are subject to investigation among these sections and the results are reported in a summary below.

Table 1

Occurrence of the Selected Discourse Markers in Different Sections of BNC

\begin{tabular}{lcccc}
\hline Discourse markers & $\begin{array}{l}\text { Spoken } \\
\text { (tokens/million) }\end{array}$ & $\begin{array}{l}\text { Fiction } \\
\text { (tokens/million) }\end{array}$ & $\begin{array}{l}\text { Magazine } \\
\text { (tokens/million) }\end{array}$ & $\begin{array}{l}\text { Newspaper } \\
\text { (tokens/million) }\end{array}$ \\
\hline you know & 502.12 & 34.38 & 5.10 & 1.53 \\
I mean & 2043.83 & 167.13 & 44.37 & 7.36 \\
oh, yeah & 6.32 & 0.06 & 0 & 0 \\
anyway & 8.43 & 11.31 & 3.03 & 1.53 \\
actually & 6.52 & 4.4 & 2.89 & 0.48 \\
Total & 2566.27 & 217.28 & 55.29 & 10.50 \\
\hline
\end{tabular}

Table 1 demonstrates that the wide use of discourse markers has been the salient property to distinguish the spoken text from the written texts such as fiction, magazine, and newspaper. Fiction stands to be a transition between spoken text and the other written texts and this may be due to the plenty use of conversations between the characters in the fictional discourse. However, the use of discourse markers seems to be found in the public discourses such as magazine or newspaper. In other words, compared with other public discourses, magazine discourse appears to be featured with the use of discourse markers. 
Starting from this line, the present study carries on with investigating the use of discourse marker via the online search on the sub-corpus of TIME, one of dominant mainstream magazine in the U.S. with the aim to look into the diachronic changes in the use of discourse markers during the past nine decades.

Take the discourse marker "you know" as an example:

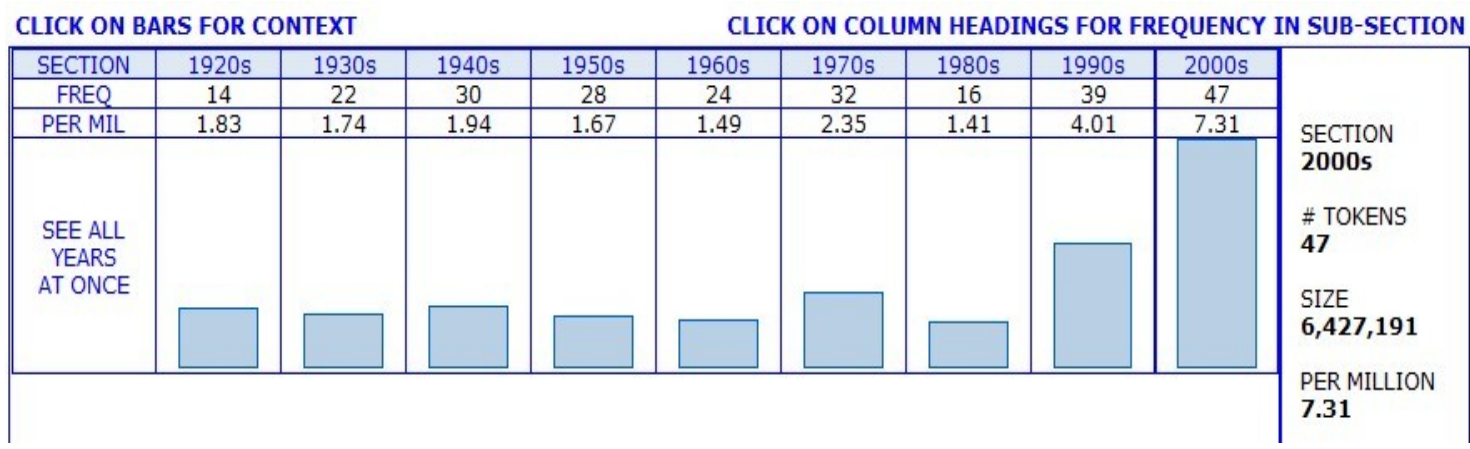

Chart 2. Occurrence of "you know" in TIME from the 1920s to the 2000s.

Chart 2 shows that the use of "you know" does not change considerably until the 1990s and there indicates a markedly increase from the 1990s to the 2000s, with an abrupt rise of standardized frequencies from being 4.01 to 7.31 .

In a similar fashion, the other four discourse markers are under investigation via TIME and the results are reported below:

Table 2

A Diachronic Overview of the Selected Discourse Markers Occurring in TIME (From the 1920s to the 2000s)

\begin{tabular}{llllllllll}
\hline DMs/(PER MIL) & $1920 \mathrm{~s}$ & $1930 \mathrm{~s}$ & $1940 \mathrm{~s}$ & $1950 \mathrm{~s}$ & $1960 \mathrm{~s}$ & $1970 \mathrm{~s}$ & $1980 \mathrm{~s}$ & $1990 \mathrm{~s}$ & $2000 \mathrm{~s}$ \\
\hline you know & 1.83 & 1.74 & 1.94 & 1.67 & 1.49 & 2.35 & 1.41 & 4.01 & 7.31 \\
oh yeah & 0.65 & 0.95 & 1.75 & 0.71 & 1.31 & 0.66 & 2.46 & 4.42 & 5.91 \\
anyway & 1.18 & 0.55 & 0.97 & 1.25 & 1.43 & 0.81 & 2.11 & 3.18 & 1.87 \\
I mean & 0.13 & 0.00 & 0.00 & 0.12 & 0.19 & 0.15 & 0.18 & 0.31 & 0.16 \\
actually & 0.26 & 0.00 & 0.13 & 0.36 & 0.75 & 0.66 & 0.26 & 1.34 & 1.09 \\
Total (per mil) & 4.05 & 3.24 & 4.79 & 4.11 & 5.37 & 4.63 & 6.42 & 13.26 & 16.34 \\
\hline
\end{tabular}

Table 2 suggests that a tendency of an increasing use of the discourse markers appears in the TIME texts, in particular, within the period from the 1980s to the 2000s. This scenario shows that TIME texts are going from being "monologic" to "dialogic" by adopting more "direct quotations" and even suggests that "dialogue" as one type of the intertextuality is prone to be the resource of message conveyance. Thus, it will be helpful to understand how this shift from being monologic to dialogic works across the different generic texts in the magazine discourse if the study identifies the preferences of using different discourse markers in different contexts. However, the corpus of TIME serves as an insightful tool in providing the assertive assumption of being moving toward "conversationalization" of magazine discourse but still remains limited in sorting out the different generic texts throughout the magazine coverage.

As a consequence, the study will resort to the sub-corpus of BNC, namely, COCA, to examine further with the preferences of discourse markers in the well-defined sections of magazine discourse and then explore the discourse functions of the discourse markers in contexts. This overall investigation will be elaborated with the instance of "you know". 
Initially, "you know" is searched on COCA and the results are reported as below:

\begin{tabular}{l} 
CLICK ON BARS FOR CONTEXT CLICK ON COLUMN HEADINGS FOR FREQUENCY IN SUB-SECTIC \\
\hline \begin{tabular}{c|c|c|c|c|c|c|c|c|c|c|} 
SECTION & SPOKEN & FICTION & MAGAZINE & NEWSPAPER & ACADEMIC & $1990-$ & $1995-$ & $2000-$ & $2005-$ \\
1994 & 1999 & 2004 & 2010 \\
\hline FREQ & 95622 & 2462 & 670 & 717 & 285 & 15804 & 23906 & 25521 & 34525 \\
\hline PER MIL & $1,097.63$ & 30.13 & 7.69 & 8.59 & 3.44 & 151.86 & 230.89 & 247.92 & 308.60 \\
\hline $\begin{array}{c}\text { SEE ALL } \\
\text { SUB- } \\
\text { SECTIONS } \\
\text { AT ONCE }\end{array}$ & & & & & & & & & \\
\hline
\end{tabular}
\end{tabular}

Chart 3. Occurrences of "you know” across the sub-sections under COCA.

Chart 3 indicates that the discourse marker of "you know" is overwhelmingly dominated in the spoken discourse and at the same time, the other media discourses such as fiction, magazine, and newspaper are also identified with the presence of "discourse markers". This result corresponds with the initial findings in the exploration on BNC. Therefore, in other words, it even asserts that there exists the use of discourse markers in the magazine discourse. This existential situation pushes to take the next steps to look into the preferences of discourse markers used in different sections.

\begin{tabular}{|c|c|c|c|c|c|c|c|c|c|c|}
\hline $\begin{array}{l}\text { Afric- } \\
\text { Amer }\end{array}$ & Childrer & Entertair & Financia & Home/Health & News/Opir & Religion & Sci/Tect & Soc/Arts & Sports & Women/Mer \\
\hline 26 & 17 & 153 & 20 & 34 & 151 & 12 & 19 & 19 & 71 & 149 \\
\hline 6.24 & 6.15 & 32.09 & 3.17 & 1.98 & 7.33 & 2.79 & 1.50 & 2.32 & 5.68 & 16.84 \\
\hline & & & & & & & & & & \\
\hline & & & & & & & & & & \\
\hline
\end{tabular}

Chart 4. The different scenario of "you know” in different sections within magazine.

Chart 4 suggests that the discourse marker "you know" occurs more frequently in the sections of "Entertainment" and "Women/Men" than the other sections, and then in "News/Opinion", "Afric-American", "Children", "Sports", and "you know" are least frequently used in the sections of "Financial”, "Religion", "Social/Arts", etc..

A global workout of the five selected discourse markers appearing in the different sections via COCA is reported as below:

Table 3

A Total Workout of the Occurrence of the Selected Discourse Markers in COCA

\begin{tabular}{|c|c|c|c|c|c|c|c|c|c|c|c|c|}
\hline DMs & Afri-Amer & Children & Entertain & Financial & $\begin{array}{l}\text { Home/ } \\
\text { Health }\end{array}$ & $\begin{array}{l}\text { News/ } \\
\text { Opinion } \\
\end{array}$ & Religion & Sci/Tech & Soc/Arts & Sports & $\begin{array}{l}\text { Women/ } \\
\text { Men }\end{array}$ & \\
\hline \multirow[t]{2}{*}{ you know } & 26 & 17 & 153 & 20 & 34 & 151 & 12 & 19 & 19 & 71 & 149 & Freq. \\
\hline & 6.24 & 6.15 & 32.09 & 3.17 & 1.98 & 7.33 & 2.79 & 1.50 & 2.32 & 5.68 & 16.84 & Per/mil \\
\hline \multirow[t]{2}{*}{ I mean } & 2 & 1 & 14 & 1 & 1 & 8 & 2 & 1 & 2 & 12 & 7 & \\
\hline & 0.48 & 0.36 & 2.94 & 0.16 & 0.06 & 0.39 & 0.47 & 0.08 & 0.24 & 0.96 & 0.79 & \\
\hline \multirow[t]{2}{*}{ oh yeah } & 2 & 0 & 3 & 0 & 1 & 2 & 0 & 4 & 0 & 3 & 3 & \\
\hline & 0.48 & 0.00 & 0.63 & 0.00 & 0.06 & 0.10 & 0.00 & 0.32 & 0.00 & 0.24 & 0.34 & \\
\hline \multirow[t]{2}{*}{ anyway } & 0 & 13 & 12 & 10 & 13 & 55 & 3 & 6 & 9 & 28 & 15 & \\
\hline & 0.00 & 4.70 & 2.52 & 1.59 & 0.76 & 2.67 & 0.70 & 0.47 & 1.10 & 2.24 & 1.70 & \\
\hline \multirow[t]{2}{*}{ actually } & 5 & 2 & 23 & 7 & 19 & 30 & 9 & 4 & 2 & 19 & 19 & \\
\hline & 1.20 & 0.72 & 4.82 & 1.11 & 1.11 & 1.46 & 2.09 & 0.32 & 0.24 & 1.52 & 2.15 & \\
\hline Total (per/mil) & 8.4 & 11.9 & 36.0 & 6.03 & 3.97 & 12.58 & 6.1 & 2.69 & 3.90 & 10.64 & 21.8 & \\
\hline
\end{tabular}


Table 3 illustrates the sections of "Entertainment" and "Women/Men" in magazine prefer to employ the discourse markers, which occupy a relatively high ratio (36\% and 21.8\%) respectively. Then, "News/Opinion", "Children", and "Sports" stand to be the secondary layer, and the frequency of each section remains relatively high (i.e., $12.58 \%, 11.9 \%$ and $10.64 \%$ for each). The ratio workout of "Financial" and "Afric-American" texts stay to be $6.03 \%$ and $8.4 \%$, still relatively higher than the others. The workout of occurrence in different sections indicated in the table suggests an ordinal sequence as follows:

Sci-technology $<$ (less than) Social/Arts $<$ Home/Health $<$ Financial $<$ Afri-American $<$ Sports $<$ Children $<$ News/Opinion $<$ Women/Men $<$ Entertainment.

This sequence can also account for in terms of the interpersonal meaning and discourse functions carried by each text type.

The text types defined in different sections vary according to their purposes of communications, for instance, the texts in the section of "Sci-technology" are aimed to inform the audience with informational meanings, thus informative and writer-oriented and hence rare use of discourse markers can be identified in such texts; the texts in entertainment function to facilitate an engagement with the readers; thus interactive and reader-oriented, therefore, such texts are dependent on the wide use of discourse markers to engage with the audiences.

Therefore, in terms of dialogic positioning, the different types contained as the contents of magazine coverage may function differently to the audiences. Some texts in the different sections are informative and less dialogic such as "Sci-technology”, "Soci/Arts”, "Home/Health”; some are interactive and more dialogic such as "Women/Men" and "Entertainment", and some stay to be moderate in between such as "Sports" and "News/Opinion", etc.. In this line, the increasing use of discourse markers in TIME during the recent 30 years even suggests that TIME magazine tends to attach importance to engaging with the audience in its topic selection and content organization, and this may give rise to that the style of magazine discourse shifts from being "informative" to being "interactive".

In a global sense, discourse markers are overused in the sections of "Entertainment" and "Women/Men", and however, the discourse marker such as the use of "anyway" appears to be preferred in the sections of "Children" and "News/Opinion". That can be attributed to the functions of discourse markers. For instance, "anyway" functions to be "concessive” and "contrastive”, which usually plays a significant role in connecting propositions and constructing authorial subjectivity in discourse. Thus, compared with other discourse markers, its interpersonal meanings seem to be weaker in terms of "engagement with audience", after all, the propositions in the sections of "News/Opinion" and "Children" are more declarative.

In a word, the occurrence of discourse markers in magazine discourse tends to be closely bound with the use of direct speech. This tendency indicates a variation and historical change across the specific contexts where the discourse markers occur. However, it will be a huge systematic project to explore the use of the discourse markers and its pragmatic implications in its context, which cannot be accomplished in this study. Thus, this study will attempt to investigate "you know", one of the selected discourse markers as an instance, to examine how it works in contexts of different times with particular focus on the textual features such as collocations and concordances through "keyword in context". This project advances to search the discourse marker of "you know" on the corpus of TIME and "you know" occurs within nine decades of the corpus for 252 times. Its occurrences within different decades increase sharply within two time periods: the 1970s and the 
2000s. Therefore, its concordances in the context of the two time periods will be examined and demonstrated as below:

Table 4

Concordances of "You Know" in the 1970s in TIME Corpus

The use of "you know" in the 1970s

1. lay there with his hind legs all spread out, you know, and his tongue hanging out of his mouth. He was (1970/06/29)

2. is the time element. Life isn't eternal, you know, and I can make three ideas in bronze for every one (1970/08/11)

3. in distress. Finally, we're all mothers, you know, and you can't expect us to live on the government (1973/02/12)

4. game playing. Lillian was relentlessly what she was, you know, as was Julia. (1977/10/03)

5. in Cholon. "We did not have to, you know, because it was a real victory. As to why we (1971/06/03)

6. 947803 "I have, you know, done a few things in my life," said Patricia (1977/01/03)

7. they say they want doesn't sound so different, you know, from what our founding fathers said they wanted. They said (1970/09/07)

8. senior citizens. “And physical Exercise, you know, is responsible for my good health. You should be in (1972/11/29)

9. They say, well, end the war, you know, stop the war in Viet Nam and bring the fellas home (1971/03/15)

10. "Il have William Buckley write a column and say, you know, that he, that he should have clemency, if you (1974/12/02)

Table 4 suggests the semantic prosody of "you know” shares the following textural characteristics:

(1) "You know” is inclined to co-occur with the expressions of negativity, such as “isn't”, “out of”, "no”, “not”, etc. (e.g., 1, 2, 3, 4, 5, 7).

(2) "You know" seems to co-occur with the "deotic" modality indicating a sense of "obligation" through the following means. For instance,

(a) "You know" seems to co-occur with the use of modal auxiliaries such as “you can't expect" (e.g., 3), "we did not have to" (e.g., 5);

(b) "You know" seems to co-occur with the use of "perfect tense" such as "I have done a few things in my life" (e.g., 6);

(c) "You know" seems to co-occur with the use of modal adjectives such as "physical exercise is responsible for my good health” (e.g., 8);

(d) "You know" seems to co-occur with the use of imperative mood or subjunctive mood such as "they say end the war, stop the war in Viet Nam” (e.g., 9), "say that he should have clemency” (e.g., 10).

These linguistic features reflect that the informational exchanges take place within an asymmetrical structure of discourse. That is, addresser (A) is providing the addressee (B) with a sort of expert knowledge that B does not own. Thus, the discursive meaning carried by "you know" is to offer "evidence". This corresponds with the information communicated through the use of "you know" in the context of "argument" (Schiffrin, 2007, p. 279). For instance,

5. in Cholon. "We did not have to, you know, because it was a real victory. As to why we (1971/06/03)

6. 947803 "I have, you know, done a few things in my life," said Patricia (1977/01/03)

In 5, the statement made in the main clause "we did not have to" is supported with a clause of reason and "you know" is inserted between two clauses, prior to the adverbial clause of cause. The use of discourse marker "you know", intensifies the legitimacy of the raising the reason. Similarly, in 6, the appearance of "you know" splits the whole statement into two elements ("I have" and "done a few things in my life"), recalling the addressee of the shared knowledge as evidential, which presupposes that the addressee has known a few things done by the speaker in his life. The speaker proposes the shared knowledge to enhance the speaker's (Partricia) evidential status in this case. 
To compare, the following table shows how "you know” works in the context of 2000s.

Table 5

Concordances of "You Know" in 2000s in TIME Corpus

The use of "you know" in the 2000s

1. a dude is Spike the Dog? Well, you know, he’s a happy-go-lucky dog. He gets a pretty big (2003/06/16)

2. "Gore told TIME last week," but, you know, I like to make a good living, and I truly (2005/08/08)

3. get some ice time. \#Oh, no, you know, I’m a union guy. I still play pickup games (2005/06/06)

4. that his Republican attackers were "the most crooked, you know, lying group I've ever seen.” Not only are (2004/03/22)

5. my knowledge, included homosexuality... It's not, you know, man on child, man on dog, or whatever the (2003/12/05)

6. up your glasses, "these letters are written, you know, not by me.” Riding on his newly christened Mainstream (2000/03/17)

7. of hypocrisies, the VietnamWar, all that, you know, that all these things could be corrected if we turned it (2003/09/22)

8. was too old and unoriginal, because in Europe, you know, there are 300 guys doing break beats. The problem was $(2001 / 06 / 11)$

9. 'd been saving for a rainy day—because, you know, they do wear out. They're just the right size (2002/03/18)

10. : Well, there was a merger, but, you know, they're like two different units. Now, I think (2002/03/22)

11. Sole true? \#A. Totally untrue. Anyway, you know, Tom didn’t want to be my assistant. I asked (2004/02/16)

Table 5 shows there emerge some new features that appear in the collocations of "you know" in the 2000s, which differ from that in the 1970s.

(1) The discourse marker "you know" tends to co-occur with the other discourse markers such as "well", "because”, "but", "anyway", etc., which conveys a concessive negotiable or contrastive meaning and these co-occurrences are distinguished from the co-occurrences with words such as "no" or "not" in the 1970s, which expresses a direct negativity;

(2) "You know" in the above cases demonstrate the speaker's evaluation to the utterance he/she produced, such as in the following instances:

3. get some ice time. \#Oh, no, you know, I'm a union guy. I still play pickup games (2005/06/06)

8. was too old and unoriginal, because in Europe, you know, there are 300 guys doing break beats. The problem was (2001/06/11)

The speakers in the both cases reflect a stance to the propositions by inviting the addressee's alignment (e.g., 3) or endorsement (e.g., 8) with the evaluation that targeted by the speakers. The evaluative function that "you know" possesses in the 2000s TIME discourse echoes with the earlier exploration of its use in oral narratives (Schiffrin, 2007, p. 281).

Overall, by examining and comparing the concordances of "you know" across the 1970s and the 2000s in TIME corpus, the discursive contexts where "you know" occurs change from one with a deontic modality to the other with a rather mundane narrative and the discourse functions of "you know" also move from being "evidential” to being "evaluative".

\section{Conclusion}

Informed within the "conversationalization" in media discourse, this study draws upon the frequency and concordance in corpus linguistics as analytic tools and attempts to investigate the uses of the selected discourse markers in magazine discourse through the sub-corpora of BNC such as BNC, TIME, and COCA. In general, there appears an increasing use of discourse markers in magazine discourse from the 1980s to the 2000s and this seems to be in relation to the adoption of "direct speech" or quotations in the coverage of magazine. The contents contained in magazine are indicated as different sections in COCA and exploration on COCA suggests that the discourse markers are most preferred by the sections of "Entertainment", "Women/Men" and then 
favorably used in "News/Opinion", and tends to be employed in "Children", and "Sports" but less favored by "Sci-technology", "Soci/Arts" and "Home/Health". That is because the text types vary and thus the interpersonal meanings carried are different. The texts with high occurrence of discourse markers function to be more interactive with the audiences and the texts with low frequency of discourse markers will be informative. These features may explain that discourse markers are sensitive to the text types or topics. Moreover, a further investigation on TIME suggests that magazine discourse gets more and more concerned with the interactivity of its contents sourcing and topic selection with its audiences. There emerges a change of the style pattern of communication from being informative, and author-oriented to being interactive and audience-oriented. Last but not least, the paper compares and analyzes the uses of "you know" as an instance between the 1970s context and the 2000s context to identify the functions of "you know" differs and changing to being more “evaluative” from being “evidential”.

\section{References}

Anderson, W., \& Corbett, J. (2009). Exploring English with online corpora: An introduction. Houndmills/New York: Palgrave Macmillan.

Atkinson, D. (1992). The evolution of medical research writing from 1735 to 1985: The case of the Edinburgh Medical Journal. Applied linguistics, 13(4), 337-374.

Baron, N. S. (2003). Why emails look like speech: Proofreading, pedagogy and public face. In J. Aitchison \& D. M. Lewis (Eds.), New media language (pp. 85-94). London and New York: Routledge.

Biber, D. (1988). Variation across speech and writing. Cambridge: Cambridge University Press.

Biber, D. (2003). Compressed noun-phrase structures in newspaper discourse: The competing demands of popularization vs. economy. In J. Aitchinson \& D. M. Lewis (Eds.), New media language (pp. 169-81). London and New York: Routledge.

Biber, D., \& Finegan, E. (1989). Drift and the evolution of English style: A history of three genres. Language, 65, 487-517.

Biber, D., \& Finegan, E. (1992). The linguistic evolution of five written and speech-based English genres from the 17th to the 20th centuries. In M. Rissanen, O. Ihalainen, T. Nevalainen, \& I. Taavitsainen (Eds.), History of Englishes: New methods and interpretations in historical linguistics (pp. 688-704). Berlin: Mouton de Gruyter.

Biber, D., Connor, U., \& Upton, T. A. (2007). Discourse on the move: Using corpus analysis to describe discourse structure. Amsterdam/Philadelphia: John Benjamin’s Pub. Co..

Chafe, W. (1982). Integration and involvement in speaking, writing, and oral literature. In D. Tannen (Ed.), Spoken and written language: Exploring orality and literacy (pp. 35-54). Norwood, NJ: Ablex.

Fairclough, N. (1992). Discourse and social change. Cambridge: Polity Press.

Fairclough, N. (1994). Conversationalization of public discourse and the authority of the consumer. In R. Kent, N. Whiteley, \& N. Abercrombie (Eds.), The authority of the consumer (pp. 253-68). London and New York: Routledge.

Fairclough, N. (1995). Media discourse. London: Edward Arnold.

Fowler, R. (1988). Orality models in the press. In M. Maclure, T. Philips, \& A. Wilkinson (Eds.), Oracy matters (pp. 135-46). Milton Keynes: Open University Press.

Fowler, R. (1991). Language in the news: Language and ideology in the press. London: Routledge.

Hundt, M., \& Mair, C. (1999). “Agile” and “uptight” genres: The corpus-based approach to language-change in progress. International Journal of Corpus Linguistics, (4), 221-42.

McEnery, T., \& Hardie, A. (2012). Corpus linguistics: Method, theory and practice. Cambridge/New York: Cambridge University Press.

Schiffrin, D. (1987). Discourse markers. London: CUP.

Schiffrin, D. (2007). Discourse markers. Beijing: WPC. 